\title{
THE EFFECT OF LOW TEMPERATURE DEGRADATION ON COLOR STABILITY OF TWO TYPES OF MONOLITHIC TRANSLUCENT ZIRCONIA CROWNS
}

\author{
Tarek Abdel Hamid*, Diaaeldin Saad Awad*, Mosaad Aly El-Gabrouny ${ }^{* *}$ and Osama Atta***
}

\begin{abstract}
Objective: To investigate the effect of artificial aging on the shade of two types of monolithic translucent zirconia crowns, manufactured using two different CAD/CAM systems.

Materials and methods: A sound human maxillary first premolar was selected to receive all ceramic crown preparation. The prepared premolar was then duplicated to produce twenty epoxy dies divided into two groups $(n=10)$ according to the constructed crowns.. Twenty Standardized monolithic translucent zirconia (10 Prettau, \& 10 Incoris TZI crowns) were CAD/CAM fabricated onto the epoxy dies and cemented using Panavia F 2.0. Vita Easy-Shade digital spectrophotometer was used to measure the color shade differences $(\Delta \mathrm{E})$ value between the selected color shade (A3 classical shade) and the color shade of the cemented CAD/CAM crowns before and after aging. The samples were aged under standard autoclave conditions for ten hours. XRD analysis was used to analyze the microstructure of both $\mathrm{ZrO}_{2}$ types before and after accerlated aging. SEM was done to examine the surface changes before and after aging. Results were tabulated and statistically analyzed using Kruskal-Wallis test and post hoc analysis .
\end{abstract}

Results: The results showed that the Prettau crowns had higher $\Delta \mathrm{E}(4.26 \pm 0.51)$ values than that of Incoris TZI crowns before (3.56 \pm 0.28$)$ aging. Also after aging Prettau showed higher $\Delta \mathrm{E}$ $(5.6 \pm 0.47)$ than that of Incoris TZI $(4.36 \pm 0.34)$. Statistical analysis showed statistical significant difference between the groups.

Conclusions: This study concluded that Incoris TZI crowns better color shade results than Prettau crowns before and after aging.

\section{INTRODUCTION}

Zirconia has three polymorphs: cubic which is stable at $2370-2680^{\circ} \mathrm{C}$, tetragonal stable between $1170-2360^{\circ} \mathrm{C}$ and monoclinic stable at room temperature. The transformation of zirconia polymorphs from cubic to tetragonal to monoclinic is accompanied by a large shear strain and volumetric increase. A small addition of certain

\footnotetext{
* Lecturer of Crown \& Bridge, Department of Crown \& bridge, Faculty of Dentistry, Suez Canal University, Ismailia, Egypt ** Professor of Crown \& bridge, Faculty Of Dentistry Suez Canal University

*** Professor of Crown \& Bridge, Department of Crown \& bridge, Faculty of Dentistry, Suez Canal University, Ismailia, Egypt
} 
special oxides such as yttria $\left(\mathrm{Y}_{2} \mathrm{O}_{3}\right)$, ceria $\left(\mathrm{CeO}_{2}\right)$, calcia $(\mathrm{CaO})$, magnesia $(\mathrm{MgO})$ and alumina $\left(\mathrm{Al}_{2} \mathrm{O}_{3}\right)$ fully or partially stabilizes the tetragonal phase of zirconia at room temperature. This transformation toughness reaction enables the material to stop crack propagation by absorbing the crack energy and increasing the crystalline volume that prevents crack growth ${ }^{1}$. Clinical experience of zirconia based restorations revealed a problem of porcelain separation or chipping which occurs due to the weak bond strength between the porcelain veneer and the underlying zirconia core ${ }^{2}$ that led to the occurrence of solid monolithic zirconia crowns (non-veneered zirconia). ${ }^{3}$

Nevertheless, despite having the transformation toughness as an advantage, it is evident that zirconia have a drawback named low temperature degradation (LTD) in the presence of moisture. In this kinetic phenomenon the polycrystalline tetragonal phase transforms into monoclinic ( $\mathrm{t}-\mathrm{m}$ phase transformations) over a temperature range of $60-300^{\circ} \mathrm{C}$ depending on the stabilizer, its concentration and the grain size of the ceramic. ${ }^{4}$

Several hypotheses were proposed to explain the cause-and-effect relationshipbetween the presence of water and the $\mathrm{t}-\mathrm{m}$ phase transformations. According to Sato and Shimada ${ }^{5}$, surface chemisorbed water induces the breakage of $\mathrm{Zr}-\mathrm{O}-\mathrm{Zr}$ bonds and the formation of $\mathrm{Zr}-\mathrm{OH}$, thereby resulting in stress corrosion. An-other hypothesis postulated that water promoted the formation of $\mathrm{Y}(\mathrm{OH})_{3}$, thus depleting the stabilizer $\mathrm{Y}_{2} \mathrm{O}_{3}$ and triggering the $\mathrm{t}-\mathrm{m}$ transformation. ${ }^{6}$ The latter assumption, however, has since been disproved. ${ }^{7}$ In an alternative explanation, the phase trans-formation was attributed to internal stresses associated with the diffusion of water radicals within the zirconia lattice, by an oxygen vacancy diffusion mechanism ${ }^{8,9}$

Although (LTD) might roughen surfaces, cause wear and decrease the hardness and strength of Y-TZP restorations ${ }^{10}$, only little information is available regarding low temperature aging of Y-TZP dental ceramics and its effect on the shade of the final restoration. ${ }^{11}$

So the aim of this study was to evaluate the effect of artificial ageing on the shade of two types of monolithic translucent zirconia crowns, manufactured using two different CAD/CAM systems

The null hypothesis tested was:

1. No difference in shade reproduction on both types of zirconia restorations

2. There no effect of artificial ageing on the shade of both zirconia restorations

\section{MATERIALS \& METHODS}

\section{Tooth selection \& sample Preparation}

A sound freshly extracted human maxillary first premolar was selected. The tooth was vertically embedded in acrylic resin base (Acrostone. Selfcure acrylic resin Egypt) with the aid of a dental surveyor (Ney Dental International, Bloomfield, Conn, USA). The tooth was prepared for allceramic crown using a standard technique. (Axial reduction with 6 degree taper and $1 \mathrm{~mm}$ rounded shoulder finish line). A specially modified dental milling machine (Nouvag AG, Dental \& Medical Equipment St. Gallerstrasse) was used for tooth preparation.

Twenty silicone molds (Dupliflex. Poligono Emporda International 17469. Vilamalla Girona, Spain) were produced from the prepared tooth. The duplication of the prepared tooth was achieved by pouring the silicone mold with translucent epoxy resin (Chemapoxy. CMB, 69 Giza, Egypt). The epoxy dies were then duplicated into twenty working stone dies for crown constructions using a scanable stone (Optic Scanning stone, ETI Empire Direct, Anaheim, CA, USA). 


\section{Crown Fabrication}

\section{Prettau crowns:}

Ten Prettau crowns were fabricated over ten working stone dies. For each crown to be fabricated a specific scan (S600, Zirkonzahn, Italy) for the respective die had to be taken for the ten dies. The crowns were designed using CAD software (Modellier, ZirkonZahn, Italy). Zirconia blocks (Prettau zirkon CAD-CAM95H22, Zirkonzahn, Italy) were milled in partially sintered stage considering of $20 \%$ shrinkage and fully sintered for 12 hours at $1600^{\circ} \mathrm{C}$. Sandblasting with $50 \mathrm{Al}_{2} \mathrm{O}_{3}$ at 3 bars was employed and then outer surface of crown was glazed.

\section{Incoris TZI crowns:}

Ten scans with cerec 3D (inEos X5, Sirona Dental Systems GmbH, Germany) of the ten epoxy dies were used with another scan of one of the fabricated Prettau crowns to produce ten Incoris TZI bio-copy crowns. Cerec software 4.3 (Sirona Dental Systems GmbH, Germany) was used for designing the restoration.

(INcoris TZI C blocks mono L, Sirona Dental Systems GmbH, Germany) of classical A3 shade were used. The blocks were milled in the partially sintered stage with the milling machine (MX 5, Sirona Dental Systems GmbH, Germany) and sintered in (inFire HTC, Sirona Dental Systems $\mathrm{GmbH}$, Germany) for 2 hours at $1510^{\circ} \mathrm{C}$. Sandblasting with $50 \mathrm{Al}_{2} \mathrm{O}_{3}$ at 3 bars was employed and then outer surface of crown was glazed.

\section{Cementation of the crown \&artificial aging}

The crowns were cemented on their corresponding epoxy dies using Panavia F2.0 following manufacturer instructions using a specilly designed device that allow application of standardized load of $3 \mathrm{~kg}$.

Artificial accelerated aging ${ }^{12-15}$ of crowns were undertaken under standard autoclave (TAU STERIL S.N.C.Via Gorizia 6/A 22073 Fino Mornasco -
Como - ITALY) conditions at $134{ }^{\circ} \mathrm{C}$ at 2 bar pressure for 10 hours.

\section{Shade Difference measurement}

A digital spectrophotometer (Vita EasyShade. Vita- Zahnfabrik, Bad Säckingen, Germany) was used to measure the color shade differences $(\Delta \mathrm{E})$ value between the selected color shade (A3 classical shade) and the color shade of the cemented CAD/ CAM crowns. The middle part of the buccal surface of each crown was selected as target area for the tip of the probe of the EasyShade device. The average of three $\Delta \mathrm{E}$ reading values was calculated and considered as final reading for the investigated restoration. $\Delta \mathrm{E}$ measurements were done twice for each sample one before aging and the second after aging. The results were recorded, tabulated and statistically analyzed using Kruskal-Wallis test and post hoc analysis.

\section{X-Ray Diffraction (XRD):}

In order to investigate the effect of aging on the crystalline structure of the investigated zirconia in this study, another four zirconia blocks were fabricated (1 Prettau+ 1 Incoris TZI) non-aged compared to (1 Prettau+ 1 Incoris TZI) artificially aged under standard autoclave conditions of $134{ }^{\circ} \mathrm{C}$ and 2 bar pressure for 10 hours. X-ray diffraction is non-destructive analytical technique to identify the crystalline structure, chemical composition and physical properties of material. The technique is based on observing the scattered intensity of an X-ray beam upon hitting a sample as a function of incident and scattered angle, polarization, and wavelength or energy. The four blocks were scanned using XRD (PAN analytical, Empyrean. The Egyptian NRC, Egypt) to determine the degree of tetragonal to monoclinic conversion.

\section{Scanning Electron Microscopy (SEM)}

The same four blocks of the XRD test were used for the electron microscope scanning test at $2000 \mathrm{X}$. The surface of the zirconia blocks was 
gold sputtered. Scanning electron microscopy (FEI. Quanta SEM. The Egyptian NRC, Egypt) of the blocks was then done.

\section{RESULTS}

The mean and standard deviation of the Prettau shade test result $(\Delta \mathrm{E})$ were recorded in Table 1 and presented in Figure 1. The statistical analysis of the $\Delta \mathrm{E}$ values for both types of zirconia tested showed statistical significance difference before and after aging using Kruskal-Wallis test and post hoc analysis (Pvalue $<0.05$ ). Prettau group showed higher $\Delta \mathrm{E}$ values than that of Incoris TZI group after aging.

TABLE (1) AE results for both types of zirconia crowns

\begin{tabular}{|c|c|c|c|c|c|}
\hline \multirow{2}{*}{} & \multicolumn{2}{|c|}{ Prettau group } & \multicolumn{2}{c|}{ Incoris Tzi } & \multirow{2}{*}{ p-value } \\
\cline { 2 - 5 } & $\begin{array}{c}\text { Before } \\
\text { aging }\end{array}$ & $\begin{array}{c}\text { After- } \\
\text { aging }\end{array}$ & $\begin{array}{c}\text { Before } \\
\text { aging }\end{array}$ & $\begin{array}{c}\text { After- } \\
\text { aging }\end{array}$ & \\
\hline $\begin{array}{c}\text { Mean } \pm \\
\text { SD }\end{array}$ & $\begin{array}{c} \pm .26 \\
0.51\end{array}$ & $\begin{array}{c} \pm .47 \\
0.56\end{array}$ & $\begin{array}{c} \pm .28 \\
\text { and }\end{array}$ & 0.34 & $* 0.0034$ \\
\hline
\end{tabular}

\section{XRD results}

Both of the Incoris TZI and Prettau zirconia had no monoclinic phase content before aging.

After aging the monoclinic phase content of Incoris TZI zirconia appeared to be $51 \%$, however for the Prettau zirconia it was to $80.4 \%$. Figure 2 \& 3 shows the XRD pattern of the Incoris TZi and Prettau (Non-Aged, Aged).

\section{SEM results:}

Scanning electron microscope study of both types of zirconia samples showed that Prettau zirconia had a rougher surface than that of the Incoris TZI zirconia. The surface roughness of both materials markedly increased after aging as shown in Figures 4, 5.

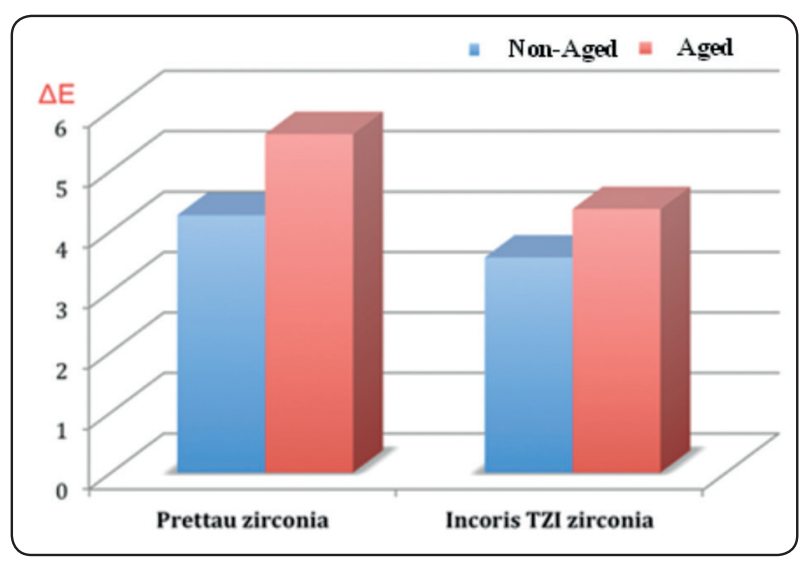

Fig. (1) Histogram showing $\Delta \mathrm{E}$ before and after aging of Prettau \& Incoris TZI Crowns



Fig. (2) XRD for InCoris TZI Non-Aged (left), and Aged (right) 


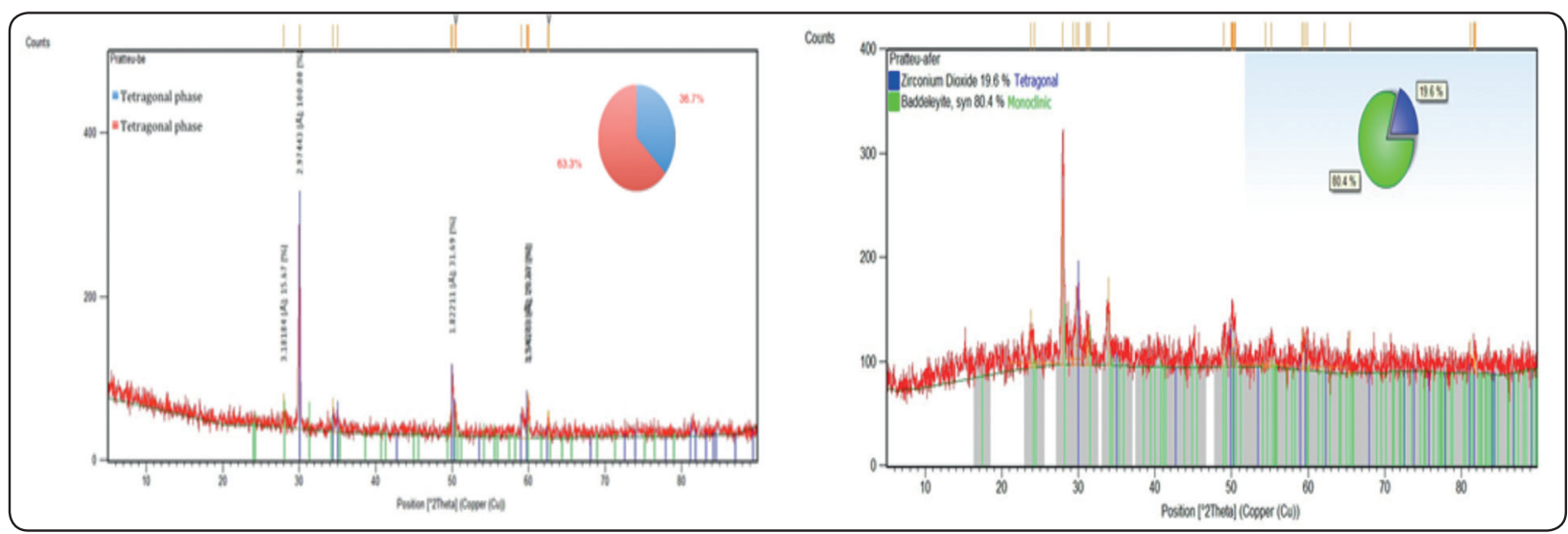

Fig. (3) XRD for Prettua Zirconia Non-Aged (left), and Aged (right
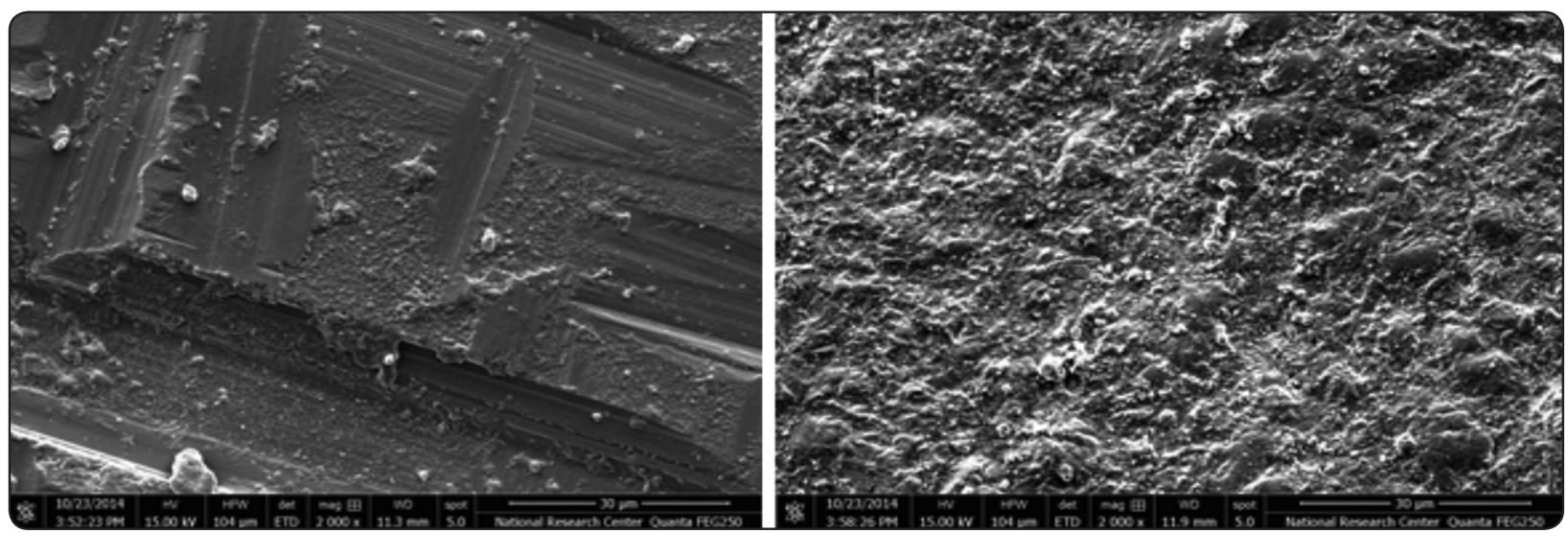

Fig. (4) SEM of Incoris TZI zirconia Before aging (left) and after aging (right).


Fig. (5) SEM of Pratteu Zirconia Before aging (Left), after aging (Right) 


\section{DISCUSSION}

The high restoration esthetic demand led to the emergence of different types of all ceramic restorations among which dental zirconia based restorations presented a promising result due to the high fracture resistance of zirconia ${ }^{16}$. However the inherent clinical drawbacks of the veneered zirconia in terms of chipping and fractures of the veneer ${ }^{17}$ and de-bonding of the zirconia restoration paved the way for development of a new restoration without the drawback of veneering layer. This led to the introduction of translucent zirconia for constructing fully contoured dental restoration that provided a hope for a fracture resistant monolithic restoration.

This in-vitro study compared two types of translucent monolithic zirconia with and without aging. Using the solid translucent zirconia restoration should consider excellent shade reproduction and stability, which is equally important to resistance to fracture and surface cracks.

There is a general agreement in the literature that Zirconia (which is one of the most commonly used ceramic restorations today) suffers a process of aging under heat, pressure and moisture that are predominant in the oral environment. It is also reported $^{18,19,20}$ that zirconia undergoes a crystalline change from metastable tetragonal to monoclinic accompanied by a volumetric increase under oral conditions.

The aesthetic of ceramic restorations depends on many factors among which the shade and translucency are reported ${ }^{21}$ to play an important role. The translucency and the opacity of any material are largely dependent on light transmission and scattering. If the majority of light passing through the material is scattered and reflected so the material will appear opaque. While if only part of the light is scattered and most of it is transmitted so the material will appear translucent ${ }^{22}$. So the interpretation of the color of any object will be affected by the physical properties of this object as if it will transmit, reflect or absorb light. Selection of all ceramic restorations depends on the degree of translucency needed, so that it mimics patient's natural dentition ${ }^{23}$. The limited translucency of the zirconia is determined by multiple combined parameters such as grain size, additives like alumina and finally the degree of sintering which supposed to be responsible for the transformation of the zirconia from the cuboidal phase to the tetragonal phase that is supposed to turn zirconia to be more translucent. ${ }^{24,25}$

The null hypothesis tested in this study were rejected since Incoris TZI crowns showed better $\triangle \mathrm{E}$ value than Prettau crowns either in the non-aged or the aged state.

In this study the die, the shape and dimensions of the crowns were all standardized. Also in order to exclude the effect of cement on the color shade of the restoration, translucent cement was used. The change of color was measured by using intra oral spectrophotometer (Vita Easyshade), which is supposed to eliminate the human variations in comparing different color shades. The intra oral Vita Easyshade device is also well reported in so many publications ${ }^{26,27}$ to be used for extra oral measurement of color difference. The value $\Delta \mathrm{E}$ is used to evaluate the accuracy and color differences ${ }^{28}$ between the selected and produced color.

Change in color $(\Delta \mathrm{E})$ is the difference between two colors in the color space. The literature ranked the change in color among dental materials as follow: $\Delta \mathrm{E}>3.7=$ very poor match, $\Delta \mathrm{E}<2=$ clinically acceptable and $\Delta \mathrm{E}<1$ visually undetectable as reported by O'Brien $\boldsymbol{W}$ et al (1991) ${ }^{29}$. It is well documented in the literature that $\Delta \mathrm{E}$ value below 1 is hardly detected visually, while $\Delta \mathrm{E}$ value between 1 and 2 may be clinically visible by some observers and higher values than 3.7 are considered clinically detectable ${ }^{30,31}$ The color shade results showed that Prettau had a higher $\Delta \mathrm{E}$ value $(4.26 \pm 0.51)$ without aging than that of Incoris TZI $(3.56 \pm 0.28)$. Scanning electron microscopy photos of both types of zirconia taken before aging in this study revealed that Prettau had a rougher surface than that of Incoris TZI. Furthermore the higher sintering temperature 
of Prettau $\left(1600{ }^{\circ} \mathrm{C}\right)$ compared to that of Incoris TZI $\left(1510^{\circ} \mathrm{C}\right)$ could be held responsible for the larger grain size of Prettau, this is in agreement with Hallman $L$ et $a^{32}$ (2013) who reported increase in the grain size due to increase in the sintering temperature. Moreover, XRD scan results of Prettau and Incoris TZI revealed that Prettau had a larger Pleomorphic tetragonal phase than that of Incoris TZI. These scientific findings could be held together to be responsible for increasing the surface roughness of Prettau, which should increase the scattering of light and subsequently decreasing translucency of the Prettau zirconia. This scientific assumption could be in agreement with Zhang $Y(\mathbf{2 0 1 4})^{33}$ who emphasized on the role of smaller grain size and diameter in increasing the translucency of zirconia. After aging Prettau persistently showed higher $\Delta \mathrm{E}$ value $(5.6 \pm 0.47)$ than Incoris TZI $(4.36 \pm 0.34)$. Once again this could be justified by the fact of increased surface roughness of Prettau than that of Incoris TZI as evidenced by SEM Photo taken after aging. Moreover the XRD scan after aging showed a higher percentage of the monoclinic phase in Prettau (80\%) compared to Incoris TZI (51\%) with subsequent increase in the grain size. The larger grain size of the monoclinic phase could have possibly allowed partial absorption and reflection of the light passing through, while most of the light could be transmitted to the underlying cement and subsequently to the underneath die. Since the cement used in the current study was translucent, so the transmitted light could possibly scattered while emerging out. The combined effect of increased surface roughness and the larger grain size of monoclinic phase of Prettau zirconia could be held responsible for possibly more light scattering that could be responsible for decreased translucency of the Prettau and subsequently increased $\Delta \mathrm{E}$ value. This explanation could be in agreement with Heffernan MJ et al (2002) ${ }^{34}$ and who reported that the amount of absorbed, reflected and transmitted light would depend on the percentage and size of crystals within the matrix and also their chemical nature.

\section{CONCLUSIONS}

Under the conditions of this study it was concluded that:

- Incoris TZI crowns showed better color stability than that of Prettau crowns both (Before \& after aging)

- Prettau zirconia showed a persistently rougher surface than that of Incoris TZI zirconia before and after aging in SEM photos.

- Prettau zirconia showed higher content of larger grain size monoclinic phase than that of Incoris TZI zirconia after aging in XRD scan.

\section{REFERENCES}

1. Klara Ėastokva, Hynek Hadraba, Jaroslav Cihlar. Hydrothermal ageing of tetragonal zirconia ceramics. Journal of Ceramics - Silikáty 48(2004), (3) 85-92.

2. Choi YS, Kim SH, Lee JB, Han JS, Yeo IS. In vitro evaluation of fracture strength of zirconia restoration veneered with various ceramic materials. J Adv Prosthodont. 2012 Aug; 4(3): 162-9.

3. Malkondu Ö, Tinastepe N, Akan E,\& Kazazoğlu E. Overview of monolithic zirconia in dentistry , Biotechnology \& Biotechnological Equipment, 30:4,644-52.

4. Özcan M. Volpato C., Fredel M. Artificial Aging of Zirconium Dioxide: An Evaluation of Current Knowledge and Clinical Relevance. Current Oral Health Reports. 2016; 3(3):193-7.

5. Sato T, Shimada M. Transformation of yttria-doped tetragonal $\mathrm{ZrO} 2$ polycrystals by anneali,ng in water. J Am Ceram Soc 1985;68:356-9.

6. Lange F, Dunlop G, Davis B. Degradation during aging of transformation- toughened $\mathrm{ZrO}_{2}-\mathrm{Y}_{2} \mathrm{O}_{3}$ materials at $250 \mathrm{C}$. J Am Ceram Soc 1986;69:237-40

7. Yoshimura M, Noma T, Kawabata K, Somiya S. Role of water on the degradation process of Y-TZP. J Mater Sci Lett 1987;6:465-7

8. Schubert H, Frey F. Stability of Y-TZP during hydrothermal treatment: neutron experiments and stability considerations. J Eur Ceram Soc 2005;25:1597-602. Guo X, Schober T. Water incorporation in tetragonal zirconia. J Am Ceram Soc 2004;87:746-8 
9. Guo X, Schober T. Water incorporation in tetragonal zirconia. J Am Ceram Soc 2004;87:746-8

10. Mitov,G. Yoshida YA, Nothdurft FP, von See C, and Pospiech $\mathrm{P}$. Influence of the preparation design and artificial aging on the fracture resistance of monolithic zirconia crowns J Adv. Prosthodont. 2016 Feb; 8(1): 30-6.

11. Kim JW, Covel NS, Guess PC, Rekow ED, Zhang Y. Concerns of hydrothermal degradation in CAD/CAM zirconia. J Dent Res 2010;89:91-5

12. Perdigão J, Pinto AM, Monteiro RC, Braz Fernandes FM, Laranjeira P, Veiga JP. Degradation of dental ZrO2-based materials after hydrothermal fatigue. Part I: XRD, XRF, and FESEM analyses. Dent Mater J 2012; 31(2): 256-65.

13. Tanaka K, Tamura J, Kawanabe K, Nawa M, Uchida M, Kokubo T, Nakamura T. Phase stability after aging and its influence on pin-on-disk wear properties of $\mathrm{Ce}-\mathrm{TZP} / \mathrm{Al}_{2} \mathrm{O}_{3}$ nanocomposite and conventional Y-TZP. J Biomed Mater Res 2003; 67A: 200-7.

14. Ban S. Reliability and properties of core materials for allceramic dental restorations. Jpn Dent Sci Rev 2008; 44:3-21.

15. Flinn BD, Degroot Da, Manci LA, Raigrodski AJ. Accelerated aging characteristics of three yttria-stabilized tetragonal zirconia polycrystalline dental material. J Prosthet Dent. 2012 oct; 108(4): 223-30.

16. Sailer I, Makarov NA, Thoma DS, Zwahlen M, Pjetursson BE. All-ceramic or metal-ceramic tooth-supported fixed dental prostheses (FDPs)? A systematic review of the survival and complication rates. Part I: Single crowns. Dent Mater. 2015 Jun; 31(6): 603-23.

17. Pang Z, Chughtai A, Sailer A, Zhang Y. A fractographic study of clinically retrieved zirconia-ceramic and metalceramic fixed dental prostheses. Dent Mater. 2015 Oct; 31(10): 1198-206.

18. Lawson S. Environmental degradation of zirconia ceramics. J Eur Ceram Soc 1995; 15(18): 485-502.

19. Flinn BD, Degroot Da, Manci LA, Raigrodski AJ. Accelerated aging characteristics of three yttria-stabilized tetragonal zirconia polycrystalline dental material. J Prosthet Dent. 2012 oct; 108(4): 223-30.

20. Lucas TJ, Lawson NC, Janowski GM, Burgess JO. Phase transformation of dental zirconia following artificial aging. J Biomed Mater Res B Appl Biomater. 2015 Oct;103(7):1519-23

21. Jiun-Yao CH. Wen-Cheng CH. Ta-Ko HU, Jen-Chyan WA, Po-Sung FU, Jeng-Huey CH, Chun-Cheng HU. Evaluation of the accuracy and limitations of three tooth-color mea- suring machines. J D Sciences. Mar 2015; 10(1): 16-20.

22. Pohjola RM, Hackman ST, Browning WD. Evaluation of a standard shade guide for color change after disinfection. Quintessence Int. 2007 Sep; 38(8): 671-6.

23. Jiang L, Liao YM, Wan QB, Li W. Effect of sintering temperature and particle size on the translucency of zirconium dioxide dental ceramic. J Mater Sci Mater M 2011; 429-35.

24. Pohjola RM, Hackman ST, Browning WD. Evaluation of a standard shade guide for color change after disinfection. Quintessence Int. 2007 Sep;38(8):671-6.

25. Nakamura T, Nakano Y., Usami H., Wakabayashi K, Hnishi H, Sekino T., and Yatani H. Translucency and lowtemperature degradation of silica-doped zirconia: A pilot study. Dent. J. 2016; 35(4): 571-7.

26. Wriedt S., Schepke U. and Wehrbein H. The discoloring effects of food on the color stability of esthetic brackets an in-vitro study. J Orofac Orthop. 2007; 68:308-20

27. Dozic A., Kleverlaan C. J., El-Zohairy A., Feilzer A. J. and Khashayar G. Performance of five commercially available tooth color-measuring devices. J Prosthodont .2007; 16:93-100.

28. Combe E. C. Notes on dental materials, sixth edition. Churchill livingstone. 1992; P 20-5.

29. O’Brien W.J., Kay K.S., Boenke K.M., Groh C.L. Sources of color variation on firing porcelain. Dent Mater 1991; 7:170-173

30. Paul SJ, Peter A, Rodoni L, Pietrobon N. Conventional visual vs spectrophotometric shade taking for porcelainfused-to metal crowns: a clinical comparison. Int J Periodontics Restorative Dent. 2004 Jun;24(3):222-31.

31. Marcelo Weber ,Denise Sabbag Haddad, Marina Gazzano Baladi, Emiko Saito Arita. Comparative spectrophotometric study of the color stability of three dental porcelains after repeated fi rings. Clin Lab Res Den 2014; 20 (3): 174-80.

32. Hallman L, Mehl A, Ulmer P, Reusser E, Stadler J, Zenobi R, Stawarczyk B, Ozcan M, Hämmerle CH. The influence of grain size on low-temperature degradation of dental zirconia. J Biomed Mater Res B Appl Biomater 2013 Jan; 100B(2): 447-456.

33. Zhang Y. Making yttria-stabilized tetragonal zirconia translucent._Dent Mater. 2014 Oct; 30(10): 1195-20.

34. Heffernan MJ, Aquilino SA, Diaz-Arnold AM, Haselton DR, Stanford CM, Vargas MA. Relative translucency of six all-ceramic systems. Part II: core and veneer materials. J Prosthet Dent. 2002 Jul; 88(1): 10-5. 